\title{
The Urban Moisture Island Phenomenon in Hong Kong
}

\author{
Zixuan Wang ${ }^{\mathrm{a}}$, Jiyun Song ${ }^{\mathrm{a}}$, Pak Wai Chan ${ }^{\mathrm{b}}$, Yuguo $\mathrm{Li}^{\mathrm{a}}{ }^{\text {,* }}$ \\ a. Department of Mechanical Engineering, The University of Hong Kong, Hong Kong, P. R. China \\ b.Hong Kong Observatory, Hong Kong, P. R. China
}

\begin{abstract}
In this study, we tended to fill in the gap of less-explored urban humidity. Our analysis revealed a more significantly rising trend in humidity in Hong Kong. A new lumped moisture model is developed to better understand and quantify the urban moisture environment. The modelling results demonstrate that a weakened city ventilation tends to increase urban air moisture. Besides, natural surfaces (vegetation and bare soil) contribute to reducing urban heat stress through evapotranspiration. It is noteworthy that the absolute humidity will start to decrease when the increment of natural surfaces reaches a threshold. On the other hand, large wall area in Hong Kong performs both sinks and storages for urban air moisture.
\end{abstract}

Peer-review under the responsibility of the organizing committee of the ICMB21.

Keywords: Urban moisture; Urban moisture island; Urban model; Urban climate; Lumped model

\section{Introduction/Background}

Previous studies tend to report the impact of rapid urbanisation on temperature. However, for humidity, despite growing interest in its significance, urban humidity is among the least studied meteorological elements modified by urbanisation. Here we develop a new moisture model inspired by the work of Silva et al. [1] and Yang et al. [2]. The absolute humidity is adopted as the variable. The lumped urban moisture model includes three main sub-models: the vertical diffusion model (VDM), the urban boundary layer (UBL) model and the urban canopy layer (UCL) model (Figure 1). A characteristic and uniform humidity value is assumed in the whole urban air volume.

\section{Model description}

A control volume that extends to UBL is defined here. The horizontal surface area $\left(A_{d}\right)$ in the city is classified into 3 categories: manmade road $\left(A_{r}\right)$, building roofs $\left(A_{b}\right)$, and natural surfaces $\left(A_{n}\right)$, and the ratio of building area to horizontal surface area $\left(\frac{A_{b}}{A_{d}}\right)$ is referred to as the plan area index $\lambda_{p} . A_{d}=A_{r}+A_{b}+A_{n}$. Wall surfaces account for a large proportion of the surface area in a high-rise compact city. The total surface area in the city $\left(A_{t}\right)$ comprises the horizontal surface area and wall surface area $\left(A_{w}\right): A_{t}=A_{d}+A_{w}$. The air storage is ignored. The governing equation of energy and mass balance in the UCL control volume can be written as following. The temperature $T_{u}$ and moisture $\omega_{u}$ are assumed to be uniform within the UCL.

The general energy balance equation is: $\rho c_{p} q_{\text {rur }}\left(T_{\text {rur }}-T_{u}\right)+\rho c_{p} q_{u b l}\left(T_{u b l}-T_{u}\right)+h_{c} A_{t}\left(T_{s}-T_{u}\right)+Q_{a n t} A_{d}=0$

The general mass balance equation is: $q_{\text {rur }}\left(\omega_{\text {rur }}-\omega_{u}\right)+q_{u b l}\left(\omega_{u b l}-\omega_{u}\right)+\beta_{w}\left(\omega_{w s}-\omega_{u}\right) A_{w}+m_{\text {road }} A_{r}+m_{\text {roof }} A_{b}+m_{E T} A_{n}+$ $m_{\text {ant }} A_{d}=0$

where $q_{u b l}$ is air ventilation rate from the UBL; $q_{\text {rur }}$ is air ventilation rate from surrounding area; T is temperature ; $\omega$ is the absolute humidity, with subscripts $u b l$, rur, and ws representing the UBL, rural area, and wall surface, respectively; $T_{S}$ is the uniform surface temperature; $h_{c}$ is the convective transfer coefficient for temperature; $\beta_{w}$ is the convective transfer coefficient for moisture; $Q_{a n t}$ is the anthropogenic heat; and $m_{\text {road }}, m_{\text {roof }}, m_{E T}$ and $m_{\text {ant }}$ represent the moisture release per unit area from road, roof, evapotranspiration and human activities, respectively.

\section{Result}

\subsection{Model validation}

The output of the lumped model is compared against measured metrological data. The input parameters are extracted from urban morphology in the Kowloon Peninsula. The model performance is evaluated through the index of agreement (IOA), root-mean-square error (RMSE) and mean bias error (MBE) to quantify bias and precision of model output (Table 1).

\subsection{The spatial and temporal profiles of temperature and humidity in Hong Kong}

Based on the historical data of $\mathrm{HKO}$ from 1961 to 2017 , temperature and humidity have increased by $1.5^{\circ} \mathrm{C}$ and $1.4 \mathrm{~g} / \mathrm{m}^{3}$ respectively, with an increasing rate of $0.23^{\circ} \mathrm{C}$ per decade and $0.25 \mathrm{~g} / \mathrm{m}^{3}$ per decade during the past 57 years. The increasing trend of temperature and moisture could be the result of both large-scale influence and local scale influence (i.e. urbanisation). The difference between urban and rural moisture is also obvious. We analyse simultaneous moisture data from one urban station (i.e. HKO) and two rural stations (i.e. TKL and TYW) during 20002017. The absolute humidity of HKO are generally higher than those of TKL, indicating a significant UMI effects (Figure 2). The increase rates 


\section{ICMB21}

of air temperature over $\mathrm{HKO}$ and $\mathrm{TKL}$ are $0.021^{\circ} \mathrm{C}$ per decade and $0.123^{\circ} \mathrm{C}$ per decade respectively, while the increasing rates of absolute humidity is $0.0627 \mathrm{~g} / \mathrm{m}^{3}$ per decade and $0.003 \mathrm{~g} / \mathrm{m}^{3}$ per decade respectively, implying that the increasing rate of urban temperature has slowed down in the last 18 years while urban air humidity has maintained a high growth rate.

\subsection{Wind and moisture}

To explore the effect of wind on moisture quantitatively, we compare the model output using different diurnal wind profiles. The wind speed input to validate the model is the hourly wind speed derived from observation, with a mean value of $1.2 \mathrm{~m} / \mathrm{s}$. Wind speed is higher during the daytime while lower at night-time. Here we compare the effects of a constant wind speed (mean value $1.2 \mathrm{~m} / \mathrm{s}$ ) with that of the observed hourly wind profile. Compared with constant wind speed profile, inadequate ventilation during the night will enhance the UMI, while large ventilation during daytime will weaken the UMI (Figure 3).

\subsection{Land use and air moisture}

The city is divided into three land use categories, i.e. man-made roads, built areas and natural surfaces. To explore the effect of land use on air moisture, we vary the ratio of natural surfaces and that of artificial surfaces. The ratio of built area to road area is set to be 2.2 , which is consistent with realistic situations. The ratio of natural surfaces varies from 0 to 0.9 with an interval of 0.1 . The results show absolute humidity in our study increases first, peaking at $f_{n}=0.6$, then slightly decreases as the natural surface ratio rises. The increase of absolute humidity as natural surface increases is clearly due to rising evapotranspiration. However, the slight decrease in absolute humidity, when the natural surface ratio is high, is unexpected (Figure 4).

Three relevant processes could be responsible for this moisture decrease phenomenon, including (1) reduced evaporation owing to reduced surface temperature, (2) reduced anthropogenic moisture owing to reduced artificial surface area (3) increased ventilation rate owing to the removal of building.

Table 1. Statistical analysis of model performance in comparison with observed air temperature and humidity at HKO station.

\begin{tabular}{llcllr}
\hline Statistics for air temperature & & Value & \multicolumn{2}{l}{ Statistics for absolute humidity } & \multicolumn{2}{c}{ Value } \\
\hline Index of agreement & IOA & 0.98 & Index of agreement & IOA & 0.98 \\
Root mean square error $\left({ }^{\circ} \mathrm{C}\right)$ & RMSE & 0.38 & $\begin{array}{l}\text { Root mean square error } \\
(\mathrm{g} / \mathrm{m} 3)\end{array}$ & RMSE & 0.15 \\
Mean bias error $\left({ }^{\circ} \mathrm{C}\right)$ & $\mathrm{MBE}$ & 0.13 & Mean bias error $(\mathrm{g} / \mathrm{m} 3)$ & $\mathrm{MBE}$ & -0.07 \\
\hline
\end{tabular}

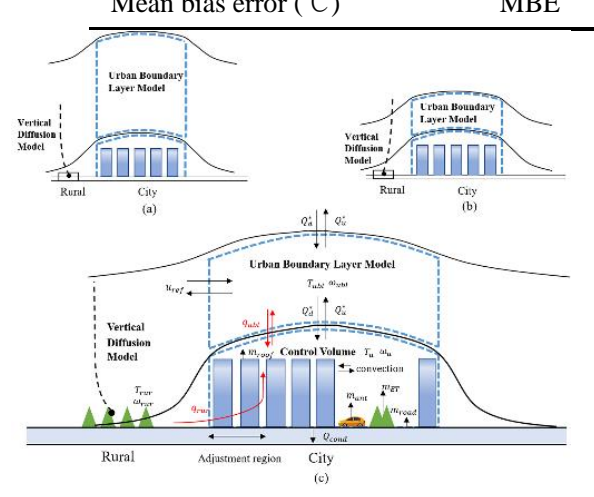

Figure 1. Simplified scheme of lumped model (based on Bueno et al. [3])

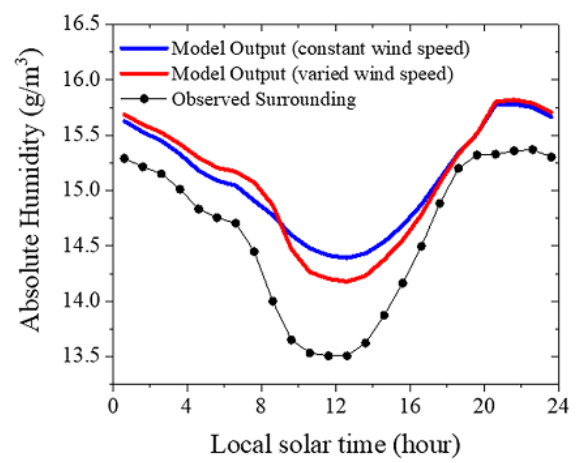

(b)

Figure 3. Model output with observed wind speed and constant wind speed

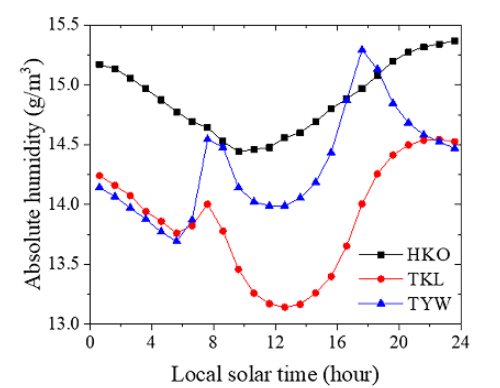

Figure 2. The diurnal profile of absolute humidity in HKO and TKL, TYW.

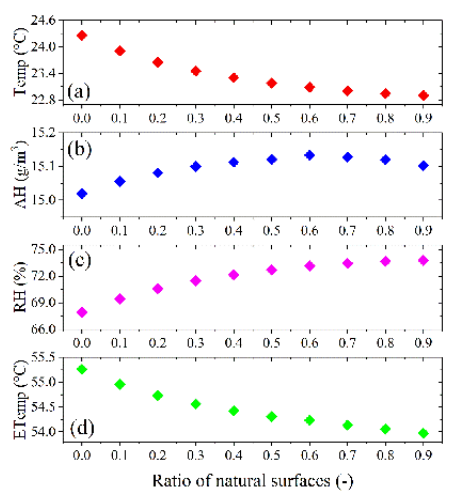

Figure 4. Variation of (a) sensible air temperature, (b) absolute humidity, (c) relative humidity and (d) equivalent temperature 
ICMB21

\section{References}

[1] Silva, H.R., Bhardwaj, R., Phelan, P.E., Golden, J.S. and Grossman-Clarke, S., 2009. Development of a zero-dimensional mesoscale thermal model for urban climate. Journal of Applied meteorology and Climatology, 48(3), pp. 657-668.

[2] Yang, X., Li, Y., Luo, Z. and Chan, P.W., 2017. The urban cool island phenomenon in a high-rise high-density city and its mechanisms. International Journal of Climatology, 37(2), pp. 890-904.

[3] Bueno, B., Hidalgo, J., Pigeon, G., Norford, L. and Masson, V., 2013. Calculation of air temperatures above the urban canopy layer from measurements at a rural operational weather station. Journal of Applied Meteorology and Climatology, 52(2), pp. 472-483. 